\title{
Constructing narrative and phenomenological meaning within one study
}

\author{
Abstract \\ Purpose - This paper argues for the articulation of the affordances of two qualitative \\ methodologies when used within one study to address the multi-dimensional nature of the \\ research phenomena.
}

Design/methodology/approach - This paper considers one example of combining narrative inquiry and phenomenological inquiry to construct new understandings of teacher learning from an Australian study.

Findings - I draw on the individual meaning-making and shared social phenomena of professional learning explored for five secondary school teachers. Findings are accessed in two ways; narrative inquiry enables the construction of unique professional learning narratives and phenomenological inquiry proposes commonalities in the teachers' experiences.

Research limitations/implications - Selected examples from the study are used to explore what may be learnt from combining two interpretative methodologies within one study with limited references to the overall research findings.

Practical implications - These qualitative methodological designs and their implementation within one study have positive influences on the multifaceted nature of the construction of meaning-making in teacher professional learning. Furthermore, using two qualitative methodologies together provide insights on the study phenomena, in this instance, highlighting the personal aspect of expert teachers' professional learning needs and the disruptive dissonance of ongoing problematics as central for the teachers throughout their professional learning.

Originality/value - This study offers one possibility for combining methodologies to access the meaning-making in teacher learning and one avenue for creating hermeneutic understanding in using the methods within this approach.

Keywords: multiple methodologies; narrative inquiry; phenomenological inquiry; meaning representations; teacher expertise; meaning-making; teacher learning; professional learning; learning problematics; developing expertise; disruptive dissonances

Paper Type: Research paper 


\section{Introduction}

The accepted use of multiple methodologies within education research provokes ongoing debate on the affordances offered by the plurality of different approaches. It is my purpose to highlight the affordances of considering phenomena through different qualitative lenses by pointing to the different understandings generated by the professional learning experiences of teachers when developing their expertise. Exploring the specific affordances of two qualitative methodologies selected for use in one Australian study requires distinguishing between the integration of two qualitative methodologies and the 'mix' of quantitative and qualitative methods (Greene, 2005). Besides outlining the use of narrative inquiry and phenomenological inquiry, I assess the extent to which specific choices provide a basis for combining qualitative methodologies.

This paper argues for articulation of the affordances of qualitative methodologies used within one study to address the realities experienced by teachers throughout the development of their professional expertise. Firstly, it is critical to understand the affordances of combining methodologies to create hermeneutic understandings for teacher professional learning. Secondly, an outline of this study constructs the meaning-making potential arising from narrative interpretations and phenomenological investigation of lived experience. Thirdly, the implications derived from using narrative and phenomenological inquiry together are examined to posit that two qualitative methodological choices substantiate the multifaceted nature of the construction of meaning-making.

\section{The affordances of combining methodologies}

Addressing education issues requires the ability to generate questions that demand an eclectic use of methodologies to explore complex phenomena of lived experience. The need for 
thinking which aims to access multiple ways of knowing and include multiple traditions in social inquiry is supported by Greene's (2005) stance of honouring, valuing and meaningfully engaging with difference in the context of the problem being addressed. Significantly, 'the juxtaposition of different lenses, perspectives, and stances' (Greene, 2005) enables the creation of new understandings and deliberations. Understanding different experiences represented through language, context and relationship not only demands ongoing questioning but a re-imaging of methodological responses to explore phenomenological difference.

The literature identifies research as 'mixed' when combining methodologies drawn from differing theoretical or paradigmatic frames (Teddlie and Tashakkori, 2012, Mertens, 2012, Tashakkori and Teddlie, 2010). Using a mixture of research methodologies was straightforward and not unusual prior to the 'paradigm wars' that came to the fore in the 1980s (Gorard and Taylor, 2004). Subsequently, the privileging of one methodological approach over another created an epistemological divide for competing research interests framed from an overarching qualitative or quantitative stance. To avoid perpetuating a methodological gulf, one way forward is to visualise a 'bricolage' that allows for the coexistence of reconciliations and ruptures in approaches (Bernstein, 1991). Imagining a theoretical 'constellation' is seen to guard against 'Othering' within normative frames (KoroLjungberg, 2004). Moreover, the diverse research traditions underpinning the synthesis of evidence across studies provides complementary affordances from differing epistemological views (Suri, 2012). Principles underlying the mix of quantitative and qualitative methods can apply to combining qualitative methodologies that integrate methods at different points of the research (Geelan, 2015, Koro-Ljungberg et al., 2013). This paper advocates the articulation of philosophical underpinnings in choosing two qualitative methodologies in one study to strengthen the research claims, whilst building on pivotal methodological understandings that 
are 'educative, not prescriptive' (Crotty, 1998)..

Considerable gains are possible when using two qualitative methodologies. For example, exploring the combined use of autobiography and ethnographic fiction provides choices in the gathering and analysis of representations for addressing issues in exemplifying and interpreting participant voice, capturing complexity of contexts, and validly positioning researcher and participant within the research (Bignold and $\mathrm{Su}, 2013$ ). An increasing trend of synthesis for qualitative studies, predominately taken up by the health professions with some instances in education in relation to teaching and learning, supports a constructionist approach to deal with methodological, epistemological and ontological issues (Major and Savin-Baden, 2011). The study presented here is one example from the many possible approaches for the gathering and analysis of meaning representations guided by two qualitative methodologies within one study.

\section{The study's use of two methodologies to understand teacher learning}

The aim of the study presented here was to understand how expert teacher learning is contingent on each teacher's meaning-making. Garnering meaning from professional learning experiences requires exploring thoughtful reflection on practice, individual reasoning and beliefs. Understanding the discursive nature of teacher learning requires focusing on how teachers 'talk about' the development of their practice (Lindqvist and Nordänger, 2010). Narrative inquiry was chosen for interpretation of the context of each unique experience. There are, however, analytical gaps in this approach if one wishes to discern commonalities across these experiences. Atkinson summarises the challenge in the following words: 'each individual life experience is simultaneously in some ways like no one else's (unique), in some ways like some others', and in some ways like everyone else's (universal)' (Atkinson, 2007). 
The need to address the universal experience of teacher learning provided the impetus for this study to be framed with a second methodological approach. Phenomenological inquiry was chosen to more deeply understand the universal meaning constructed through individual teacher experiences. Harnessing the two methodologies enabled a realistic resonance for the teachers reviewing narratives constructed through the study and therefore credible recognition of participant experiences by other teachers. This meaning-making is iterative, in which hermeneutic understanding is created through evolving interpretation (Walshaw and Duncan, 2015). The ensuing discussions address how the two methodologies narrative inquiry and phenomenological inquiry - enabled hermeneutic movement within the unique story of lived experience and more deeply amongst the phenomena of universal experience.

\section{Searching within unique stories: Narrative inquiry}

Over the years, Clandinin and her collaborators have made a strong case for narrative, arguing that understanding created through narrative inquiry allows for a reinterpretation of an individual's being in the world through the temporality and conceptuality of their social interactions (Clandinin and Rosiek, 2007). Interpretive fluidity occurs between understandings of experience throughout past, present and future. People continually recreate meaning through the process of ongoing reflection upon their experience. The creation and interpretation of experience through narrative (Clandinin and Connelly, 2000, Clandinin, 2007) identifies poignant moments and events in the shaping of teacher professional identity (Connelly and Clandinin, 1999). Other arguments for the narrative approach have suggested that insight on experience posits a greater self-understanding through 'interactive sensemaking' (Kelchtermans, 2009) and the 'transactional' authority of learning experiences (Craig, 2011). Additional thematic cross-analysis of individual narratives also offers broader 
Constructing narrative and phenomenological meaning within one study

understanding of teachers' perspectives of learning (Thomas et al., 2014).

\section{Delving deeply into universal experience: Phenomenological inquiry}

Phenomenological inquiry offers researchers pre-reflective meaning-making as a tool for delving deeply amongst the phenomena of universal experience, to contextualise the commonalities across unique lived experiences. Pre-reflective meaning focuses on the lifeworld by attending to the experience of everyday phenomena (Dall'Alba, 2009) in order to make visible, aspects of consciousness not previously articulated in experience (Moran, 2000). Determining the phenomena of everyday lived experience requires capturing the changeable nature of experience and searching for deeper meaning often embedded at an implicit level.

A methodological construct therefore attends to the hermeneutic circle by acknowledging an overlap in the experiences of researcher and participant (Kvale, 1983). The researcher captures essential phenomena from within the context of the experience and suspends imposed meaning to enable the construction of new phenomena. Finally, contextualisation of the meaning of the phenomena enables the sharing of understanding about this experience (Denzin, 2002). The use of a phenomenological approach that provides 'narrow and deep' analysis of individual learning amongst experiences and interpretation of consciousness may be viewed as complementary to other approaches (Creely, 2016).

Therefore, the study presented here draws on the theoretical frames offered by two qualitative methodologies to explore self-understanding and learning within the different contexts of each teacher's experience and to capture the attendant meaning-making in the development of their expertise as universally experienced phenomena.

\section{Combining narrative and phenomenological methodologies}




\section{Research context and question}

This study was conducted in Australia with secondary school teachers to address the overarching research question, how do expert teachers construct meaning from their personal professional development and their approach to their own learning? (Patterson, 2017). Snowball or chain sampling (Liamputtong and Ezzy, 2005) across different school systems increased variation and the initial cross-section of contacts then distributed an email to their nominated teachers. The initial contacts identified teachers they viewed as operating at high levels of expertise, as supported by the descriptors of teaching expertise criteria (Refer Appendix A) developed from the literature with the proviso that it was not an exhaustive or all-inclusive list of people's ideas of a good teacher. Combined purposive sampling and criteria sampling enabled the nomination of expert teachers who were then given the opportunity to volunteer to be in the study. The iterative gathering and analysis of experience resulted in five teachers participating in the study. Clarifying the sampling process was crucial, as evidenced in two instances when I discovered that the research intention had been misunderstood resulting in a broadcast email to all teachers in one school. Analysis methods drawn from narrative inquiry and phenomenological inquiry were used to access the multifaceted nature of expert teachers' construction of meaning from their personal professional learning.

\section{Methodological choice}

Exploring the complexity of individual experience and the phenomenological difference amongst the universality of experience necessitated the use of two qualitative methodologies. Consideration was given to connecting the affective and cognitive aspects of experience to achieve new understanding of teacher learning through storytelling (Breault, 2009). The advantage of providing realistic contexts for learning through storytelling acknowledged a 
need to extend what is understood into the realm of the unknown or 'strange' rather than just reinforcing knowledge of the familiar (Egan, 1986). Narrative inquiry provided two frameworks to inform the gathering and analysis of representations in sequencing a structured story of individual experience and interpreting the contextual modes expressed throughout the unique story. Distinctively, stories 'create a reality of their own' (Bruner, 1986) and so demand a deeper understanding 'better achieved by looking from two points of view at once' (Bruner, 1986). In order to achieve an additional perspective in understanding the construction of meaning in expert teacher learning a conventional approach of using a quantitative methodology was not required. Rather, phenomenological inquiry was needed to gain deeper understanding of the universality of teacher experience. The challenge of moving between the unique and universal meaning (Atkinson, 2007) was addressed in the study by attending to the perpetual 'Being-demanding-to-be-said (un être-à-dire) that precedes our actual saying' (Ricœur, 2008). Therefore, two methodologies privileged the unique lifeworld experience and so the research design addressed qualitative principles of rigour to stimulate and identify insights that would recognisably resonate with other teachers.

\section{Qualitative principles of rigour}

The qualitative principles of verisimilitude, appetency and transferability provided rigour for the study (Pinnegar and Daynes, 2007, Van Maanen, 1988, Clandinin and Connelly, 2000), centring on transferability rather than generalizability (Lincoln and Guba, 1985).

Verisimilitude requires the reasonable appearance of truth and reality in representations (Clandinin and Connelly, 2000) and appetency is the recognition of shared hopes and goals (Patterson, 2017). The interpretation of expert teachers' beliefs and views of their professional learning experiences should be recognisable and realistically resonate with participants and their experience. The transcripts and individual narratives were shared with 
each teacher to ensure they made sense and represented the reality of their experience. Appetency was evident in the interpretative approach used with expert teachers, which encouraged a mutual aspiration for seeking interpretative meaning from their experience. Appetency and verisimilitude for the study required trustworthiness in reporting findings and in understanding external factors, such as professional status and accreditation, which presented tensions in recognising teaching expertise.

The degree to which other teachers relate the research findings to their own experience supports transferability - the ability to recognise findings within the research field and applicability to future research endeavours. Transferability for the study relied on eliciting the perspectives of expert teachers as a credible account of their experience for description and interpretation. Seeking authentic views of expert teachers in a reflective approach towards their own learning was supported through both narrative and phenomenological approaches that address the psychological and linguistic dimensions (Merriam, 2002) of research participants' experience. The analysis addressed the coherence of findings (Riessman, 2008) to strengthen the degree to which themes drawn from the expert teachers' views would readily transfer to the experience of others within the Australian context.

The discussion that follows describes the overall process used to gather and analyse individual experiences, as illustrated in Figure 1. 


\section{First}

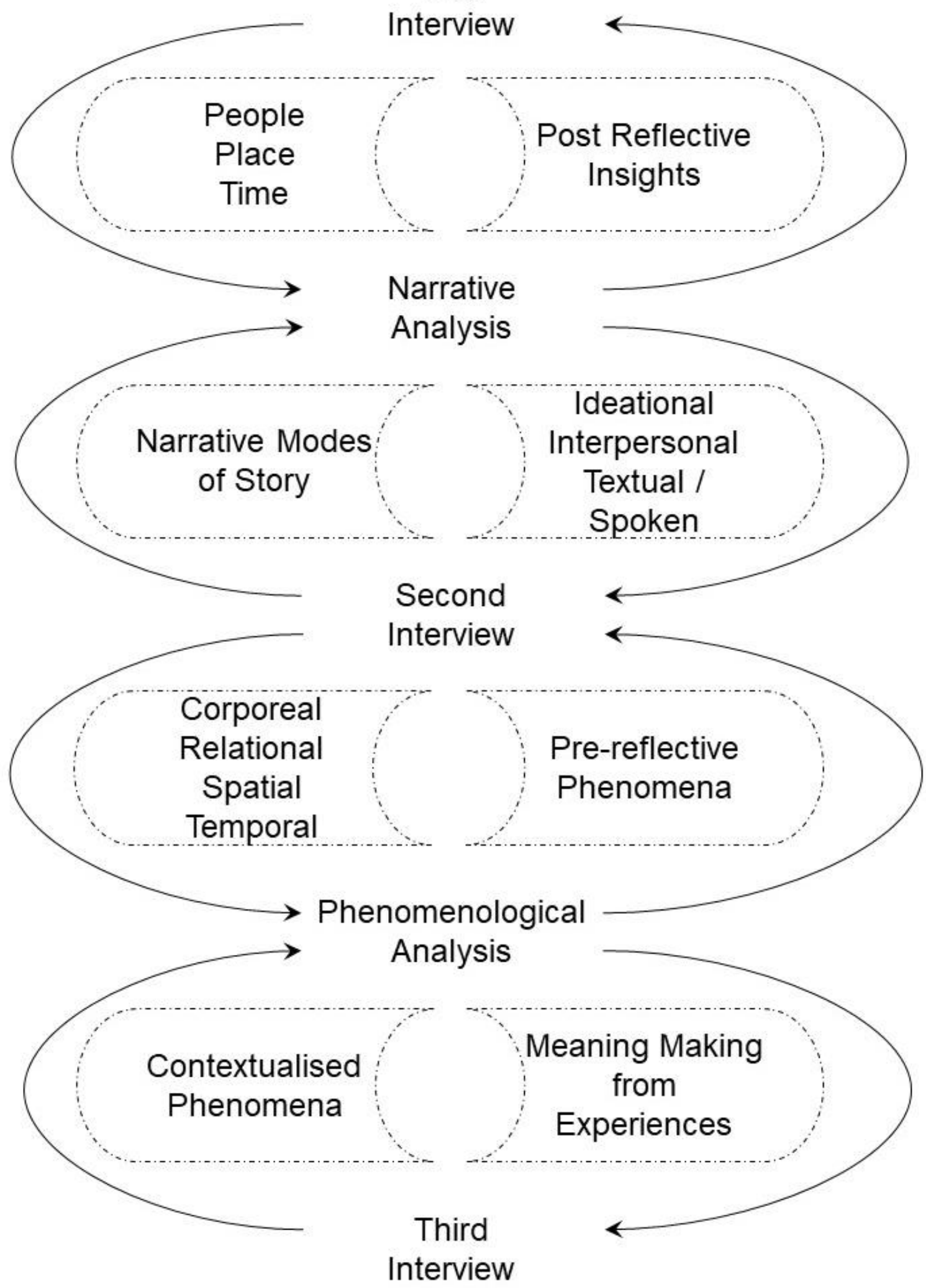

Figure 1: Combining narrative inquiry and phenomenological inquiry for gathering and analysis of meaning representations. 


\section{Gathering of meaning representations of experience}

The experience of each teacher was explored during three interviews. Two semi-structured face-to-face interviews were one to one-and-a-half hours' duration each for initial gathering of narrative oral history experiences and the subsequent phenomenological lifeworld interview. A third phone interview of one hour's duration enabled the teachers to offer final reflections. Determining saturation of findings within the three-interview process was designed to reduce repetition as outlined below.

The first interview for each participant and confirmation of transcript by the participant was completed prior to preliminary interpretations and commencing the second interview and subsequent confirmation of this second transcript. The first interview was conducted with each participant before commencing the second interview, and similarly for the third interview, as one way of circumventing any repetition in information that did not provide new meaning or insights (Liamputtong and Ezzy, 2005). A draft narrative was provided to each participant prior to completing the third and final interview.

The number of participants in the study was dictated by saturation of information and mindfulness of 'no longer learning anything new' (Seidman, 1991) throughout the iterative gathering and analysis. The development and use of the criteria for purposive sampling enabled the nomination of expert teachers identified as demonstrating expertise in teaching and learning. This purposeful, non-randomized selection of the teachers for the study limits the subsequent interpretations of findings as they are not generalizable and may not be representative of all teachers viewed as expert. However, the interviewing methods allowed the gathering of "in-depth information from those who are in a position to give it" (Cohen et al., 2007) in ways that might resonate with other teachers. The first interview prompts were developed to incorporate a sharing of life history (Clandinin and Connelly, 2000), the second 
for contextualising lived experiences within a phenomenological frame (van Manen, 1997) and the third for articulating individual sense making about the meaning of developing expertise and reflecting on participation in the research.

Participant teachers recounted their experience through a narrative oral history interview to explore their personal professional development and learning. An interview guide provided prompting questions such as:

- Reflecting on a typical day/ week in your teaching, how would you describe your learning experience?

- What aspects of the professional learning you have experienced assisted in your growth in expertise?

- Could you describe other elements or aspects that could improve your learning experience?

After a timeframe varying from several weeks to a few months to allow for teacher reflection on the initial transcription, the participating teachers then provided their thoughts on aspects representative of their emotional and intellectual meaning-making through a phenomenological lifeworld interview. The prompting questions in the interview guide for this lifeworld interview evoked connections and meanings in relation to the four existential concepts (spatiality, corporality, temporality, relationality) of van Manen (1997). Example of prompts used were: I was interested in understanding your thoughts on what your own learning means to you for each of these four areas;

- The person you are?

- The spaces that you need and inhabit?

- The influence of interpersonal relations? 
- The relationship of past, present and future across your experiences?

After participant review of the second transcript and an initial draft of their professional leaning narrative, a third interview was used to clarify the representations made. Each teacher then reflected on their understanding of expertise in relation to their participation in the study. The use of three interviews spanning several weeks to months enabled a coherent construction of understanding to flow from participant to researcher (Kvale and Brinkmann, 2009).

\section{Analysis of the meaning-representations of experience}

The three interviews described above for the gathering of experiences and the analysis of interview transcripts described below were not linear in nature. The iterative analysis resulted in a spiralling process, as represented in Figure 1, which allowed for interpretative narrative construction and phenomenological reflection of expert teacher's experience.

Narrative analysis. A professional learning narrative for each teacher was crafted as outline below.

The initial analysis interpreted teacher stories within a sequence of abstract, orientation, complicating action, evaluation and coda following Kvale and Brinkmann (2009). This approach entailed the construction of unique narratives that focused on individual teacher learning and the changes to teaching approaches and beliefs that evidenced their learning.

The interview transcripts were also analysed using a second narrative framework to explore the context and meaning construct through different 'forms of telling' (Riessman, 2002). Three levels of contextual meaning were interpreted as: 
- Ideational - denoting the referential meaning and conceptual understanding represented by each expert teacher,

- Interpersonal - concerning the context of each teacher's social and personal relationships, and

- Textual or Spoken - signifying the context conveyed through the syntactic expression of language rules and the semantic use of various words or symbols.

Contextual modes can be apparent within the co-construction process of the teacher telling their story or during the crafting of a story.

Tensions in narrative space. The interaction between the personal and the social aspects of participants' stories, their continuity throughout past, present and future; and the situation creating a notion of place (Clandinin and Connelly, 2000) were identified across the structured story sequence and the contextual mode of narrative analysis. A coding of people, time and place in this metaphorical space within each teacher's unique learning were eventually discarded as less substantial representations of the subsequent phenomenological analysis.

The unnecessary overlay of the people, time and place representations in my analysis was evidence of the acknowledged tensions of thinking and writing at the boundaries of a metaphorical space. Being mindful of reducing nuanced experiences to formulaic representations when using narrative analysis frameworks (Clandinin and Connelly, 2000), the representative categories were then abandoned so as not to overshadow the uniqueness of experience. Repeated purposeful listening to each interview while reviewing the interview transcripts enabled an audit of the coded information to elucidate the teachers' representations of meaning. I felt my interpretation exhibited 'good Gestalt' (Kvale, 1983) in that the components had unity within and across each of the frameworks and allowed for the 
creation of each teacher's narrative and the subsequent phenomenological analysis.

Consequently, the narrative analysis comprised the teacher's story and contextual modes of interpretation, capturing each teacher's voice within their professional learning narrative. Teacher voice was represented through the quotations used within each participant teacher's story as based on their authenticity, adequacy and plausibility, and on the explanatory, invitational quality of narrative inquiry. The 'explanatory, invitational quality' of the teacher's narrative is demonstrated through the rhetorical questions the teacher posed or the clarification of their thoughtful actions that they provided. The following quotes from two teachers provide examples:

And it's learning all those things which are a challenge but then you'd get bored if you didn't have a challenge wouldn't you? [Teacher 4]

I don't know how to put it [pause], it's not breaking them but I don't know whether it's just being really honest and almost letting them see that I'm human. [Teacher 2]

The teacher's narrative contains an 'authenticity' when experiences are validated with the realities of the lifeworld by invoking accurate and genuine examples. These realities are acknowledged through anecdotal statements from teachers, as shown by these two quotes:

\footnotetext{
And the head of faculty sat down with me and goes "this paper is not very good". So I went and got the syllabus and I said "well here's where the questions came from" and he's like "oh okay". [Teacher 1]

I remember all this exactly because I had to fill in so much paperwork for immigration so I remember the timescales and everything very clearly. [Teacher 3]
}

Additionally, the teacher's story exhibits an 'adequacy and plausibility' by referring to experiences that align to those of another and in considering the likelihood that they may be the same or somewhat different. This aspect of story is evidenced through the two quotes below. 
I thought "yeah, I can be like that" and not exactly the same but I can operate a lot more like him. [Teacher 1]

I was still thinking about his philosophy about wanting to teach in not such an ideal school but try and make a difference. But having said that I've done what a lot of teachers have done. [Teacher 5]

Individual voice was evident in the unique contextual significance analysed through the narrative modes of storytelling.

Phenomenological analysis. Analysis of representations of meaning incorporated a sequence of steps to search for phenomena specific to the professional learning of the teachers' experience. This analysis ascertained meaning of the teachers' experience with the reinterpretation of the phenomena.

Firstly, interviewing required the researcher to deconstruct prior conceptions, attend to the hermeneutic circle, capture the phenomena, and suspend, as much as possible, imposed cultural preconceptions (Kvale, 1983). Subsequent analysis on the anecdotal reflections from the first and second interviews required bracketing of essential meaning, constructing the meaning of phenomena, contextualising these phenomena within the lifeworld, and ascertaining meaning of the teachers' lived experience (Denzin, 2002). Phenomenological constituents in relation to the development of expertise and professional learning were then identified across all interview transcripts. The relative importance and connection of meaning for each of the teachers emerged from the unique narratives. Finally, identification of the phenomenological constituents across the teachers' learning experiences was achieved through an ongoing process of phenomenological writing (van Manen, 1997).

'Selfother' in phenomenological writing. Ongoing phenomenological writing required 'a participatory mode of consciousness' in being aware of the 'selfother' (Heshusius, 1994). This consciousness required the researcher to become immersed in the teacher's reflection on 
experience to understand the teacher's construction of meaning from their lifeworld experiences.

The initial four existential concepts used for prompting - spatiality, corporality, temporality, relationality (van Manen, 1997) - were originally coded as themes of analysis. However, this coding was discarded as ongoing rereading across all three interview transcripts and rewriting of the professional learning narratives for each teacher prompted new understandings of the experiences within each lifeworld. Continued phenomenological writing created more implicit representations within the teachers' experience and enabled identification of phenomenological constituents.

The phenomenological analysis highlighted commonalities in the lifeworld for the five teachers in the study. It was evident that relational and communicative perspectives were central to the teachers' attitudes and beliefs towards learning for themselves and others. Cultivating an 'insightful presence' (Lindqvist and Nordänger, 2010) provided greater selfunderstanding for the teachers and resonated in their understanding of others. The participant teachers' perspectives of empathetic understanding and non-competitive collegiality provided meaning to the development of their expertise. Empathetic understanding was evident for Teacher 4 who continually noted that "those little moments are really good" in relationships with students where felt and understood as "real". However, a cautious disposition and more selective collegiality was demonstrated by two teachers in their approach to collegial relationships. Teacher 3 felt less confident and "intellectually intimidated" by some colleagues in non-supportive and competitive school environments because "some people are a bit superior". Teacher 5 perceived their experience as being in competition with school leaders and colleagues, where the relational and communicative tensions experienced with colleagues by this teacher hindered a perspective for growing collegial relationships. 
Additionally, the phenomena of three problematics were identified as influential in the development of expertise for the teachers. The degree to which these problematics were addressed by each teacher in the study distinctly impacted their approach to their own professional learning. Unique disruptive dissonances were apparent in the findings of three problematics negotiated by all the teachers as follows:

- To what extent is there a risk in isolating my experience from communicative, collaborative pedagogy?

- In what ways should I approach uncertain challenges as developmental opportunities?

- How do I articulate being an expert through the seemingly impossible possibility of becoming an expert?

The phenomenological constituents of disruptive dissonances and the meaningmaking for the teachers stems from their experience of these dissonances. Disruptive dissonances are apparent in the relational and communicative spaces in which the teachers interact in teaching and learning: peopled classrooms, school communities, professional cooperatives and societal discourses. Characteristically, the relational and communicative spaces require the teachers' openness to developing awareness of self and others, the crossing of boundaries, both practical and theoretical, and the negotiation of contested meaning surrounding personal professional expertise. A dissonance may have certain degrees of positive and negative disruption depending on the way in which a teacher responds to it.

Combining narrative and phenomenological inquiry with this study enabled the development of my notion of an ontological third space, as characterised through the work of Lefebvre (1991), Soja (1996), and Zeichner (2010). The findings provided a basis to argue that disruptive dissonances are phenomenological constituents of the participant teacher's lifeworld and are evident in negotiating the problematics essential for their learning. 


\section{Concluding thoughts for a way forward}

This study demonstrated the meaning-making possible in using two qualitative methodologies within one study. This example of combining narrative and phenomenological inquiry articulates how deeper insights on research phenomena are accessed and engages with conversations in the literature on the use of methodologies (Koro-Ljungberg et al., 2013).

Using the lens of narrative inquiry offers descriptive frameworks to explore, interpret, explain and translate the individual experiences of expert teachers. Details of their unique stories created rich professional learning narratives encapsulating the learning trajectory for the teachers who participated in the study. A narrative mode of interpretation contributed to understanding the unique learning experiences of each teacher. Recognition of contextual factors that shaped their personal professional development, as well as acknowledging the individual attitude and beliefs on their own learning allowed the teachers to retain ownership

of their unique pedagogy. Creating narrative accounts is part of a formative learning approach for teachers participating in narrative inquiry (Latta and Kim, 2009). The reliance on storytelling within a teaching culture is evident in transmitting meaning, such as complexities of context, and building relationships in professional learning, through reflection on self and with others. The study presented here allowed narrative inquiry to act as a learning tool in which participant expert teachers reflected on the significance of others in their professional learning and shared the self-understanding they had constructed through a unique approach to their own learning.

Use of the lens of phenomenological inquiry in the study was guided by the question: 'How could this subject live through these constituents and what are the interrelationships among them for the subject as lived through?' (Giorgi, 1989). The generation and interpretation of meaning from the life experiences aimed to create understanding 
recognisable in and transferable to the lives of other teachers. A central challenge for me was to question and, as much as possible, suspend imposed cultural meanings - putting aside the everyday understanding of experience to interpret the unexpressed phenomena previously constrained within the participants' experience. In this sense, phenomenology provided a framework for thinking about and interpreting the lifeworld phenomena of the professional learning experience for the teachers in the study. As a researcher, I could posit the prereflective meaning constructed through the unique experience of professional learning, represented as universal constituents for the expert teachers who participated in the study.

The phenomenological inquiry of the study tentatively proposed phenomena as uniquely understood existential constituents. Perspectives reverberated throughout the development of the teachers' expertise in exhibiting relational caring and supportive interactions towards their students, colleagues and the broader school community. Their perspectives indicated the value they placed on understanding the learner and on their professional relationships with colleagues. The teachers presented an 'outward' orientation in which they lived and experienced 'encounters in a different way' (Lindqvist and Nordänger, 2010). In this way, the teachers' perspectives afforded insights on the development of their expertise. At times, they could uncritically attune to the pre-reflective meaning of their experience through insightful presence, expressing the importance of their perspectives within the relational and communicative spaces of teaching and learning. Further reinterpretation of phenomena suggested three ongoing problematics as central for the teachers throughout their professional learning.

The harnessing of attributes of qualitative approaches encourages conversations on the use of multiple methodologies for ongoing learning from diverse research perspectives for education research. The two qualitative methodologies used in the study provided one interpretive perspective from the divergent and varying interpretive perspectives that are 
possible. A modification of the methodological approach for this study provides implications for future research. Using an interactive research process could benefit the professional learning of participating teachers by utilising a community actively involved in researching their own practice. An interactive research process can then draw on individual and collective learning to enable epistemological and ontological revelations of 'shared understanding and new affordances for acting and learning' (Ohlsson and Johansson, 2010).

Searching within unique experiences and delving more deeply amongst universal lived experience created understandings of expert teacher learning that are recognisable and transferable to the lives of other teachers. The selection of two qualitative methodologies enabled two chosen approaches to explore and interpret interrelated phenomena to posit the significance of personal professional learning within the lived constituents of their experience and their interrelationships for the five teachers in the study. The demonstration of the teachers' attitudes and beliefs about their own learning highlighted a distinctive approach that emphasised the personal aspect of their professional learning needs. The post-reflective narrative of individual experience and the revelation of essential phenomena from prereflective meaning represented one possible interpretation of lifeworld experiences. Consequently, in demonstrating the affordances of using methodologies for uncovering new understandings of teacher learning, this paper supports the use of multiple methodologies within one study to gain diverse understandings for research in education.

Acknowledgements. [Submitted in the separate cover page.]

\section{References}

Atkinson, P. 2007. The Life Story Interview as a Bridge in Narrative Inquiry. In: CLANDININ, D. J. (ed.) Handbook of narrative inquiry: mapping a methodology. Thousand Oaks, California: Sage Publications.

Bernstein, R. J. 1991. The new constellation: the ethical-political horizons of modernity/postmodernity, Cambridge, Polity Press.

Bignold, W. \& Su, F. 2013. The role of the narrator in narrative inquiry in education: construction and co- 
construction in two case studies. International Journal of Research \& Method in Education, 36, 400414.

Breault, R. A. 2009. Distilling wisdom from practice: Finding meaning in PDS stories. Teaching and Teacher Education, 26, 399-407.

Bruner, J. S. 1986. Actual minds, possible worlds, Cambridge, Mass, Harvard University Press.

Clandinin, D. J. 2007. Handbook of narrative inquiry: mapping a methodology, Thousand Oaks, CA, Sage Publications.

Clandinin, D. J. \& Connelly, F. M. 2000. Narrative inquiry: experience and story in qualitative research, San Francisco, California, Jossey-Bass Inc.

Clandinin, D. J. \& Rosiek, J. 2007. Mapping a Landscape of Narrative Inquiry: Borderland Spaces and Tensions. In: CLANDININ, D. J. (ed.) Handbook of narrative inquiry: mapping a methodology. Thousand Oaks, CA: Sage Publications.

Cohen, L., Manion, L. \& Morrison, K. 2007. Research Methods in Education. 6th ed. Hoboken: Taylor and Francis.

Connelly, F. M. \& Clandinin, D. J. 1999. Shaping a professional identity: stories of educational practice, New York, Teachers College Press.

Craig, C. J. 2011. Narrative Inquiry in Teaching and Teacher Education. In: KITCHEN, J., PARKER, D. C. \& PUSHOR, D. (eds.) Narrative inquiries into curriculum-making in teacher education. 1st ed. Bingley: Emerald Group Publishing.

Creely, E. 2016. 'Understanding things from within'. A Husserlian phenomenological approach to doing educational research and inquiring about learning. International Journal of Research \& Method in Education, 1-19.

Crotty, M. 1998. The foundations of social research: meaning and perspective in the research process, St Leonards, Allen \& Unwin.

Dall'alba, G. 2009. Learning to be Professionals. Springer Netherlands.

Denzin, N. K. 2002. The Interpretive Process. In: MILES, M. B. \& HUBERMAN, A. M. (eds.) The qualitative researcher's companion. Thousand Oaks, London: Sage Publications.

Egan, K. 1986. Teaching as storytelling: an altemative approach to teaching and the curriculum, Chicago, University of Chicago Press.

Geelan, D. R. 2015. While Heisenberg is not looking: the strength of 'weak measurements' in educational research. The Australian Educational Researcher, 1-10.

Giorgi, A. 1989. One type of analysis of descriptive data: Procedures involved in following a scientific phenomenological method. Methods, 1, 22.

Gorard, S. \& Taylor, C. 2004. Combining methods in educational and social research. Maidenhead: Open University Press.

Greene, J. C. 2005. The generative potential of mixed methods inquiry. International Journal of Research \& Method in Education, 28, 207-211.

Heshusius, L. 1994. Freeing Ourselves From Objectivity: Managing Subjectivity or Turning Toward a Participatory Mode of Consciousness? Educational Researcher, 23, 15-22.

Kelchtermans, G. 2009. Who I am in how I teach is the message: self-understanding, vulnerability and reflection. Teachers and Teaching: Theory and Practice, 15, 257 - 272.

Koro-Ljungberg, M. 2004. Impossibilities of Reconciliation: Validity in Mixed Theory Projects. Qualitative Inquiry, 10, 601-621.

Koro-Ljungberg, M., Mazzei, L. A. \& Ceglowski, D. 2013. Diverse ways to fore-ground methodological insights about qualitative research. International Journal of Research \& Method in Education, 36, 131144.

Kvale, S. 1983. The qualitative research interview: A phenomenological and a hermeneutical mode of understanding. Journal of Phenomenological Psychology, 14, 25. 
Kvale, S. \& Brinkmann, S. 2009. InterViews: learning the craft of qualitative research interviewing, Los Angeles, Sage Publications.

Latta, M. M. \& Kim, J.-H. 2009. Narrative Inquiry Invites Professional Development: Educators Claim the Creative Space of Praxis. Journal of Educational Research, 103, 137-148.

Lefebvre, H. 1991. The production of space, Oxford, Eng. ; Cambridge, Mass., Blackwell.

Liamputtong, P. \& Ezzy, D. 2005. Qualitative research methods, South Melbourne, Oxford University Press.

Lincoln, Y. S. \& Guba, E. G. 1985. Naturalistic inquiry, Beverly Hills, Calif., Sage Publications.

Lindqvist, P. \& Nordänger, U. K. 2010. Encounters in metaphors: Connecting the bridgeheads of teachers' practical knowledge and professional language. International Journal of Pedagogies \& Learning, 6, 49-61.

Major, C. H. \& Savin-Baden, M. 2011. Integration of qualitative evidence: towards construction of academic knowledge in social science and professional fields. Qualitative Research, 11, 645-663.

Merriam, S. B. 2002. Qualitative research in practice: examples for discussion and analysis, San Francisco, California, Jossey-Bass.

Mertens, D. M. 2012. What Comes First? The Paradigm or the Approach? Journal of Mixed Methods Research, 6, 255-257.

Moran, D. 2000. Introduction to phenomenology., London, Routledge.

Ohlsson, J. \& Johansson, P. 2010. Interactive Research as a Strategy for Practice-based Learning: Designing Competence Development and Professional Growth in Local School Practice. In: BILLETT, S. (ed.) Learning through practice: Models, Traditions, Orientations and Approaches. Dordrecht; London: Springer.

Patterson, C. 2017. Accessing Narrative Oral History and Phenomenological Lifeworld Experience Through Interviews: Professional Learning Experience of Expert Teachers. SAGE Research Methods Cases [Online].

Pinnegar, S. \& Daynes, J. G. 2007. Locating Narrative Inquiry Historically: Thematics in the Turn to Narrative. In: CLANDININ, D. J. (ed.) Handbook of narrative inquiry: mapping a methodology. Thousand Oaks, California: Sage Publications.

Ricœur, P. 2008. From Text to Action Essays in Hermeneutics II. London: Continuum.

Riessman, C. K. 2002. Narrative Analysis. In: MILES, M. B. \& HUBERMAN, A. M. (eds.) The qualitative researcher's companion. Thousand Oaks, London: Sage Publications.

Riessman, C. K. 2008. Narrative methods for the human sciences, Thousand Oaks, Sage Publications.

Seidman, I. E. 1991. Interviewing as qualitative research: a guide for researchers in education and the social sciences, New York, Teachers College Press.

Soja, E. W. 1996. Third space: Journeys to Los Angeles and other real and imagined places, Malden, MA, Blackwell.

Suri, H. 2012. Epistemological pluralism in research synthesis methods. International Journal of Qualitative Studies in Education, 1-23.

Tashakkori, A. \& Teddlie, C. 2010. Epilogue: Current Developments and Emerging Trends in Integrated Research Methodology. In: TASHAKKORI, A. \& TEDDLIE, C. (eds.) Handbook of mixed methods in social and behavioral research. Thousand Oaks, California: Sage Publications.

Teddlie, C. \& Tashakkori, A. 2012. Common 'Core' characteristics of Mixed Methods Research: A review of critical issues and call for greater convergence. American Behavioral Scientist, 56, 774-788.

Thomas, U., Tiplady, L. \& Wall, K. 2014. Stories of practitioner enquiry: using narrative interviews to explore teachers' perspectives of learning to learn. International Journal of Qualitative Studies in Education, 27, 397-411.

Van Maanen, J. 1988. Tales of the Field. On Writing Ethnography, Chicago, The University of Chicago Press.

Van Manen, M. 1997. Researching lived experience: human science for an action sensitive pedagogy, London, Ontario, Althouse Press. 
Walshaw, M. \& Duncan, W. 2015. Hermeneutics as a methodological resource for understanding empathy in on-line learning environments. International Journal of Research \& Method in Education, 38, 304-319.

Zeichner, K. 2010. Rethinking the Connections Between Campus Courses and Field Experiences in Collegeand University-Based Teacher Education. Journal of Teacher Education, 61, 89-99.

Author Biography - Carmel Patterson is an associate of the Faculty of Arts and Social Sciences at the University of Technology Sydney. Her professional expertise is in developing teacher pedagogy, articulating curriculum, integrating digital technologies in learning, and encouraging enacted personal professional learning. She facilitates teacher professional learning in schools, consults on the accreditation of professional learning courses provided by private enterprise and universities, and presents papers at education research conferences both nationally and internationally.

Acknowledgements - The author wishes to thank Professor Sandy Schuck for valuable methodological discussions and guidance. The author is grateful for the feedback and support provided by Dr Diane Tasker, Dr Jane Hunter, Dr Susanne Francisco and Dr Prue Salter.

\section{Appendix A Teaching expertise criteria}

The categories of criteria below represent the variety of expertise relevant to a teacher's field of practice or teaching discipline. This is not an all-inclusive or an exhaustive list in representing people's ideas of a good teacher.

\section{Current teaching role.}

Value attributes and diverse abilities.

- Learning orientation: to challenge their expertise for their own learning; to mentor other teachers, demonstrate learning leadership and encourage learning in others

- Creative: to develop original approaches without prompting; to leverage their strengths to forge their area of expertise; to utilise diverse improvisational ability

- Critically perceptive: to show multidimensional awareness and sensitivity to the learning context; to appraise and analyse information and arguments 
- Initiative: to embark on new ideas or approaches without prompting; to sustain and complete a self-initiated project

- Reflective: to reflect on their goals and achievements through continual reappraisal

- Perseverance: to work in difficult circumstances; to monitor and modify for success; to frame their experience against mistakes and failures

Teaching knowledge and practice.

- Demonstrate knowledge of their subject content and how to teach that content

- Demonstrate knowledge of their students and how they learn

- Plan, assess and report for effective learning

- Communicate effectively with their students, parents and colleagues

- Create and maintain safe and challenging learning environments through the use of classroom management skills

- Continually improve their professional knowledge and practice

- Actively engaged members of their profession and the wider community

\section{Professional achievements.}

Professional knowledge application.

- Using knowledge in original ways to problems of acknowledged importance or new expressions of knowledge or creative insight

- Sharing knowledge to a professional or academic community

- Contributing to collaborative or educational research projects or involvement in commercialisation of educational knowledge

- Drawing on knowledge from a range of sources and applying it to professional practice, and acknowledged by appropriate peer recognition 
- Serving on committees or panels, in relation to research/professional activity

Professional knowledge exposition.

- Contributions of a scholarly kind to a professional organisation, learned society or community group, or to scholarly journals and other professional publications

- Authorship, direction or execution of performances, productions, exhibitions, or designs appropriate to the discipline or medium concerned

- Original publication of a book, audiovisual recording, or computer software, or technical drawing/architectural and industrial design/ working model

- Individual exhibition of original work or representation of original art

- Openly competitive awards.

- University or school awards, competitions, or teaching prizes; International or national competitive awards. 